By acceptance of this articte, the publisher or recipient acknowledges the U.S. Government's right to retain a nonaxclusive, rovalty.tree licanse in and to any copyright covering the article.

\title{
CONCEPTUAL DESIGN OF A HOLLOW CABLE CONDUCTOR FOR THE LARGE COIL PROGRAM
}

John W. H. Chi

Westinghouse Electric Corporation

Fusion Power Systems Department

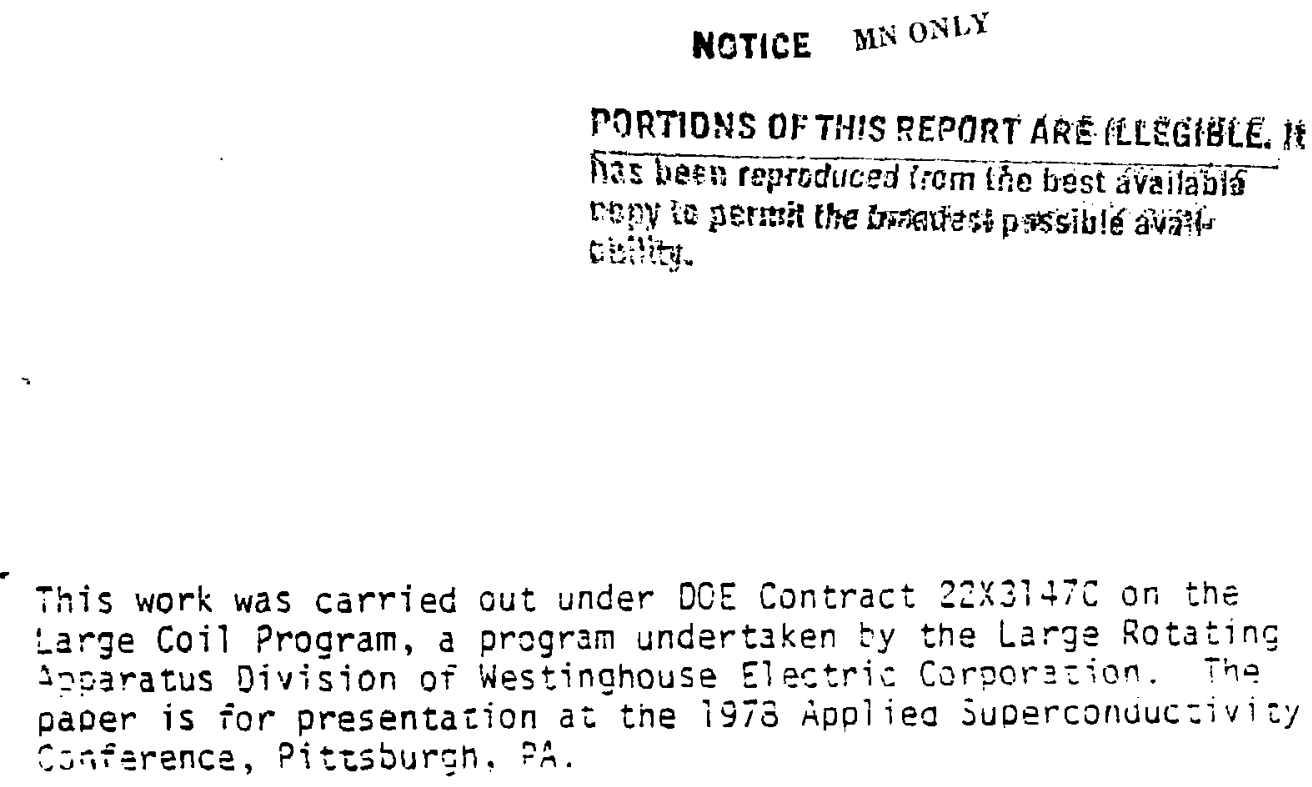

This report was prepared is an accuunt of wotk

spunsored by the United States Gnvernment. Nesther the

United States nut the United States Department of

Eneray. nut any of their employees, nor any of thet

contractors, suhcuntractorss, ut their employees, makes

any wartanly, express or implied. ot assumes any legal

lizhility at respunsihilisy fim the accuracy, cumpieteness 


\section{INTROOUCTION}

Nestingnouse selected forced flow, supereritical helium-cooled $\mathrm{Nb}_{3} \mathrm{Sn}$ hollow sable conductors for the Large Coil Porgram (LCP) (1). A number of requirements and constraints were specified for the design of the model coil. Those that have direct and indirect impacts on the conductor design were: 1) The conductor must recover spontaneously to the superconducting state when half a turn is Iriven normal initially; 2) Total refrigeration load must be less than $550 \mathrm{~W}$ when the coil is operating with the full current; 3) Total refrigeration load must be less then $100 \mathrm{~W}$ when the coil is operating at $80 \%$ of the full current; 4) The peak magnetic field is to be 8 teslas; and 5) The maximum conductor surrent is 16,000 A. The conceptual TF coil is a pancake-wound device where each pancake of aluminum contains a number of conductor slots. Each slot accommodates 5 parallel turns. Details are described elsewhe-e ${ }^{(2)}$.

The basic conductor concept selected consists of cabled triplexes, initially enclosed in a round pipe stainless steel jacket and then compacted to a square configuration with the desired void fraction (3). Examination of a typical consutor cross section (See the figure below) suggested a number of uncertainties sict affest the conducior design. They are: The uniformity of helium fiow in the interstices of the twisted strands, the uniformity of current flow among zie strands during conductor recovery, the load-bearing capability of the coninctor, the heat transfer coefficients and the friction factors for twisteds:rands compacted hollow cable conductors. These uncertainties and the lack of - For experience in the design of superconducting devices with hollow cabled - -luductors suggested that conservative assumptions be used. This paper discusses ina design aporoach and the selection of a reference design. 


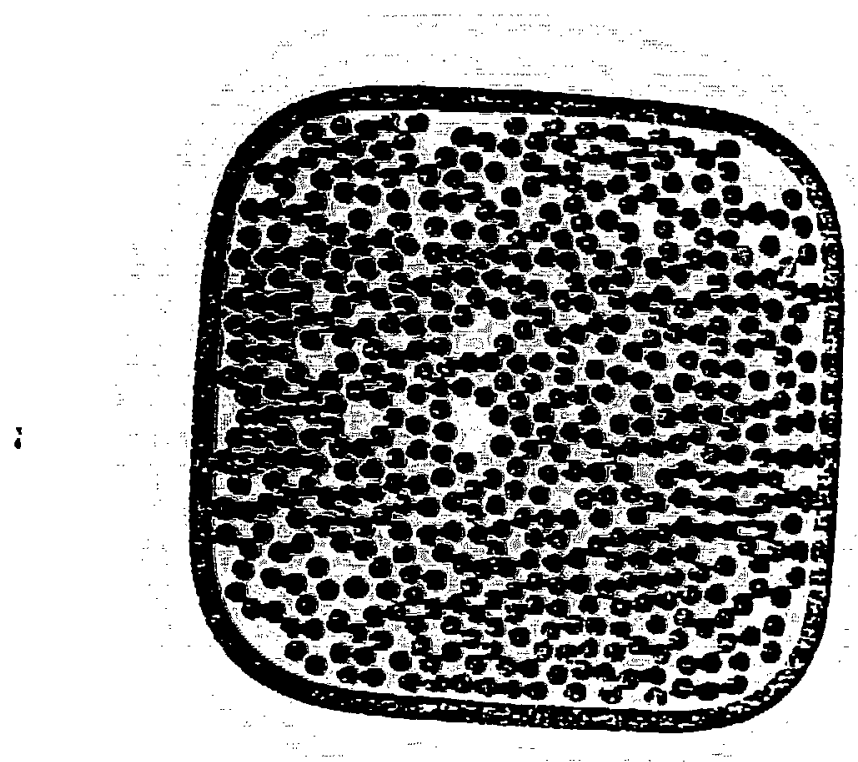

Figure 1. Cross Section of a Prototypical LCP Forced Cooled Conductor (567 Strands). 


\section{DESIGN APPROACH AND REFERENCE CONCEPT}

The design of a conductor-cooling concept to meet the specified requirements and constraints of the LCP is essentially a transient heat transier proolem where the conductor selected must meet simultaneously the stability criteria and the reirigeration load constraints. The approach to the conceptual design was to perform initial scoping calculations based on simplified models and conservative assumptions. A reference concept was then selected from the results. This was followed by detailed transient conductor cooldown analysis to verify the stability of the conductor.

It can be shown that a conservative conductor design criterion can be derived from the equation of energy of the conductor such that the overall heat transfer coeificient raquired for stability is given by the relation:

$$
u \geq \frac{J_{n c} I \rho_{c u}}{u p_{c}\left(T_{c}-T_{f}\right)}
$$

where inc is the current density in the non-copper portion of the conductor strands, $I$ is the transport current, $P_{r 11}$ is the maximum electrical resistivity of the copper stasilizar (irradiated), $T_{c}$ is the maximum critical temperature, $T_{f}$ is the bulk fluid temperature, ${ }^{2} \mathrm{Cu}$ and $T_{c}$ occur at the location of the peak magnetic

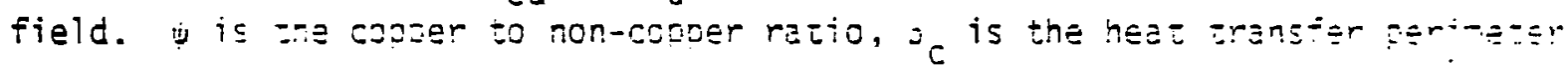
of the conquctor strands, assumej to de $75 \%$ of the totai perimeter. The overaii heat transion cosficient is related to the film coefficient $h$, the insulation thickness o and the themal conouctivity of the insulation $k_{i n}$ :

$$
n=\frac{1}{\frac{1}{U}-\frac{5}{k_{i n}}}
$$

The film heat trarsfar coefficient $h$ can be related to the helium mass velosity through a neat transier correlation. The helium mass velocity decermines the

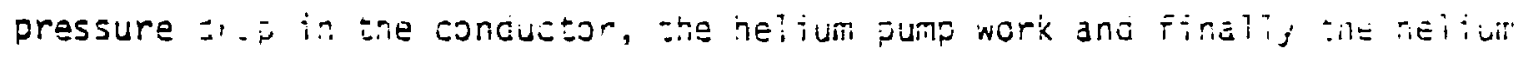
refrigeration ioad due to the pumo work. To minimize the hei im pump work, the overall heat : ransfer ccefficient must be rinimized while simultareously 
satisiying the stability criterion. In the absence of a heat transfer correlation specifically applicable to hollow cable conductors, the one developed by Giarratano ${ }^{(4)}$ for forced convective supercritical helium based on data obtained for turbulent flow in smooth tubes was assumed with a multiplicative factor of 1.5 (in the scoping calculations) to take into account the anticipated better heat transfer in the twistad strands when compared to smooth tube:.

\section{Conductor Desicn Variables}

The criterion given in Equation 1 contains the conductor design parameters $\psi$, Jnc, and $\mathrm{PC}$, which are in turn dependent on a number of other design variablas such as the conductor cross-sectional area, the helium (void) fraction, the number and the size of the conductor strands, the cabling configuration selected, and the insulaticn thickness. To minimize helium pump work, it is desirable to meximize the conducsor cross-sectional area. However, considerations of structural requirements and the sotal number of conductor turns resulted in a maximum conductor a-oa not to exceed $4 \mathrm{~cm}^{2}$ for the helium plus the conductor strand crosssectiscial are's. The number of conductor strands and the strand diameter depends on the type of cabling configuration considered. The selection of a cabling configuration wa based or considerations of the void, the void size distributions ard the desire for to:3l transposition of the strands (to minimize AC losses). Some possible cabiing configurations and the corresponding total number of

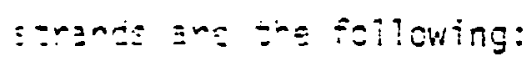

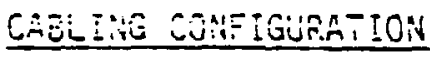

$$
\begin{aligned}
& \sum \therefore 3+3 \times 7 \\
& \Xi \therefore \Sigma . . \Sigma \times 3 \\
& j \times j \times 7 \times 7 \\
& \Xi \because j \therefore: \because 3 \therefore 7
\end{aligned}
$$

NO. OF STRANDS

is9

$2 \div 3$

441

567
FRACTIION OF ACTIVE STRANDS

FOR TOTAL TRANSPOSITION 
Cabling operations ending in 4 groups of conductors were not considered because this configuration tands to yield excessively large voids. The larger the number of groups of strands in the cabling configuration, the better is the void, and void size distributions.

\section{Parametric Analyses}

It becomes evident that there are a number of possible trade-offs which can be elucicated through parametric analysis. Because of the large number of design variables rivolved, a number of the conductor parameters were fixed for the parametric analysis. The current density in the non-copper portion of the conductor was set at $25,000 \mathrm{~A} / \mathrm{cm}^{2}$. The current density in the superconductor was fixed at $100,000 \mathrm{~A} / \mathrm{cm}^{2}$ (20\% of short sample value at $8.3 \mathrm{~T}$ and $50 \%$ of short sample value at $11 \mathrm{~T}$ ). The conductor (heliuli plus conductor strand) area was taken to be $4 \mathrm{~cm}^{2}$. The hel ium void fraction was selected to be 0.4 , the insulation thickness was $10 \mathrm{H}$, the thermal conductivity of the insulation was assumed to be $1.3 \times 10^{-3} \mathrm{~W} / \mathrm{cm}-\mathrm{K}$, the transport current was set at 15,000 A for the prel iminary scoping calculations, and the friction factor was assumed to be $20 \%$ greater than thosa obtained by Hoenig for a 57 strand round pipe hollow cable conductor ${ }^{(5)}$.

It was postulated that because of the nonuniformity of the void sizes, conductor strands in contact with the highest helium flow velocities would recover first. :ne strands would then carry a greater current than the average, resulting in a "cascaded recovery" process $(6)$. The strands recovering last are in contact with the minimum fiow velocity. The strands in contact with the miritimum mass velocity, imin, thus control the recovery of the conductor. The ratio of the nominal to in imum mass velocities was assumed to be three, based on a preliminary correlation of Hoenig's friction factor data. The nominal mass velocity, $G_{\text {nom' }}$, is needed to establish the pressure drop and the helium pump work. The relation zetween $G_{\min }$ and $G_{\text {nom }}$ is discussed in more detail in a companion paper ${ }^{(6)}$.

The efiers: of the cabling configuration and the number of strands on the - irsna tin-ter, total hea: transfer surface area and the coppper-to-non-copper : :io ar $\equiv-2 w n$ in Table 1 . Based on the preliminary calculations on various lear ics. $\quad \therefore$ d he rasulitant refrigeration loads, a tentative limit of 300 watis was $: . . \quad$ : reirigeration load for helium pump work. For a pump efficiency 
TABL.E 1

PRE: IMINARY PARAMETRIC ANALYSIS

\section{EFFECT OF: CONIUUCTOR OESIGN PARAMETERS ON REFRIGERAION LONOS}

15,000 A CONDUCTOR

\begin{tabular}{|c|c|c|c|c|c|}
\hline $\begin{array}{c}\text { TYPE OF } \\
\text { CONDIICTOR }\end{array}$ & $\begin{array}{l}\text { NO. OF } \\
\text { STIRANDS }\end{array}$ & $\begin{array}{l}\text { FRACT ION } \\
\text { OF ACT IVE } \\
\text { STRANDS } \\
\end{array}$ & $\begin{array}{c}\text { STRAND } \\
\text { DINMETER, COII }\end{array}$ & $\begin{array}{l}\text { COPPER TO } \\
\text { NON-COPPER } \\
\text { RATIO } \\
\end{array}$ & $\begin{array}{l}\text { REFRIGERAT ION } \\
\text { FOR lle PUMP } \\
\text { WOIKK } \mathrm{W} \\
\end{array}$ \\
\hline $\begin{array}{l}\text { FULLYY TRANISPOSED } \\
\text { (DUMMY STRANDS) }\end{array}$ & $\begin{array}{l}189 * \\
567 *\end{array}$ & $\begin{array}{l}0.86 \\
0.86\end{array}$ & $\begin{array}{l}0.127 \\
0.073\end{array}$ & $\begin{array}{l}2.44 \\
2.44\end{array}$ & $\begin{array}{r}2114 \\
305\end{array}$ \\
\hline $\begin{array}{l}\text { NOT FULLY } \\
\text { TRANSPOSEO) } \\
\text { (IND DIMMNYY STRANDS) }\end{array}$ & $\begin{array}{l}189 * \\
567+\end{array}$ & $\begin{array}{l}1.0 \\
1.0\end{array}$ & $\begin{array}{l}0.127 \\
0.073\end{array}$ & $\begin{array}{l}3.0 \\
3.0\end{array}$ & $\begin{array}{r}437 \\
79\end{array}$ \\
\hline $\begin{array}{l}\text { FULLY TRANSPOSED } \\
\text { UHIFORM VOID SIZES }\end{array}$ & $\begin{array}{l}189 \star \\
567 \uparrow\end{array}$ & $\begin{array}{l}1.0 \\
1.0\end{array}$ & $\begin{array}{l}0.127 \\
0.073\end{array}$ & $\begin{array}{l}3.0 \\
3.0\end{array}$ & $\begin{array}{l}56 \\
10\end{array}$ \\
\hline $\begin{array}{l}13 \times 3 \times 3 \times 7=189 \\
13 \times 3 \times 3 \times 3 \times 7=567\end{array}$ & $\begin{array}{l}\text { INITIAL VOID } \\
\text { INITIAL VOID }\end{array}$ & $\begin{array}{l}=0.79 \\
=0.86\end{array}$ & $\begin{array}{l}\text { COMPACTEO } \\
\text { COMPACTEO }\end{array}$ & $\begin{array}{l}.4 \\
.4\end{array}$ & \\
\hline
\end{tabular}


of 50\%, the maximum pump work allowed is 150 watts. The helium pump work calculated for the various cabling configurations showed that among the cables investigated only the 507 strand, $7 \times 3^{4}$ cable can meet the stability criteria and this pump work goal. Obviously, a cable with greater than 567 strands can also meet this goal; however, it would compromise other design goals/considerations. For example, the next potentially attractive cables are 1539 strands $\left(9 \times 3^{4}\right), 1701$ strands $\left(7 \times 3^{5}\right)$, etc. However, these would result in appreciably smaller strand diameters and higher manufacturing costs. In addition, the subchannel sizes would be considerably smaller. The 567 strand cable was therefore selected as the reference cable conductor. A lattice braided conductor was calculated for a comparison. This conductor can achieve significant reductions in the helium pump work and the refrigeration load because full transposition can be attained without incorporating any dummy strands.

The specifications of the reference conductor concept are given in Table 2 below.

TABLE 2

SPECIFICATIONS FOR THE REFERENCE CONDUCTOR CONCEPT

CONDUCTOR OIMENSIONS INSIDE THE

STAINLESS STEEL JACKET

CONDUCTOR CURRENT

NUMBER OF CONDUCTOR STRANDS

NUMBER OF INACTIVE STRANDS

STRAND DIAMETER

INSULATION THICXNESS

WIRE OIAMETER

COPFER TO NON-COPPER RATTO

LIEL IUM (VOID) FRACTION

Z: Sn to Nb RATIO
$2 \mathrm{~cm} \times 2 \mathrm{~cm}$

$16,000 \mathrm{~A}$

$567 !$

81

$0.0734 \mathrm{~cm}$

17 microns

$0.07 \mathrm{~cm}$

1.92

0.40

3 to 1 


\section{Verification of Conductor Stability}

Verification of the stability of the conductor was carried out by transient recovery anaiysis of the reference conductor using zero-dimensionat and onedimensional models and the TAP-B computer code. The code solves simultaneously the equation of energy of the conductor and the equations of energy, motion, continuity and state of the fluid by finite difference analysis. Three models were used in the analysis. The zero-dimension model adopted the peak local magnetic fieid of $8.3 \mathrm{~T}$, while the $1 / 2$ turn (one-dimension model) assumed a fieid distribution in a region where the magnetic fields are the highest. The third model is essentially the same as the second model. The basic differenca is that only $25 \mathrm{~cm}$ of the half turn was assumed to be driven normal initially. The analyses were performed by driving the conductor normal initially with a given amount of energy input. The recoverability of the conductor was then analyzed by varying the helium flowrate based on minimum subchannel mass velocities and the total conductor flow area. The details of the analyses will not be given here, but the results are summarized in Figure 2. The helium flowrate limited by the refrigeration constraint is shown on the figure. The starred point corresponds to the hand-calculated conditions.

It becomes apparent from Figure ? that the basic stability criteria used for the scoping analysis compares well with the computer analysis and that the zero-dimension model provides a conservative design. The transient analyses show that the conductor can recover to the superconducting state (within the refrigeration constraint) with the conductor initial1y driven to $21 \mathrm{~K}$. This corresponds to an adiabatic energy input of some $650 \mathrm{~mJ} / \mathrm{cm}^{3}$ (s irand volume).

\section{CONCLUSIONS AND RECOMMENDATIONS}

The good agreenent between the "steady-state" criterion (Equation 1) and the "zerodimension" transient model merely suggests that consistent assumptions were used in both se:s of analysis. The uncertalntiu: ielineated earlier remains to be rasolved. Their resolution may pemit $\therefore$ tion of the conservative design assumptions nade. In particular, press: ior Ewisted-strand, compacted cable co ip, heat transier and siability data are urgently needer. 


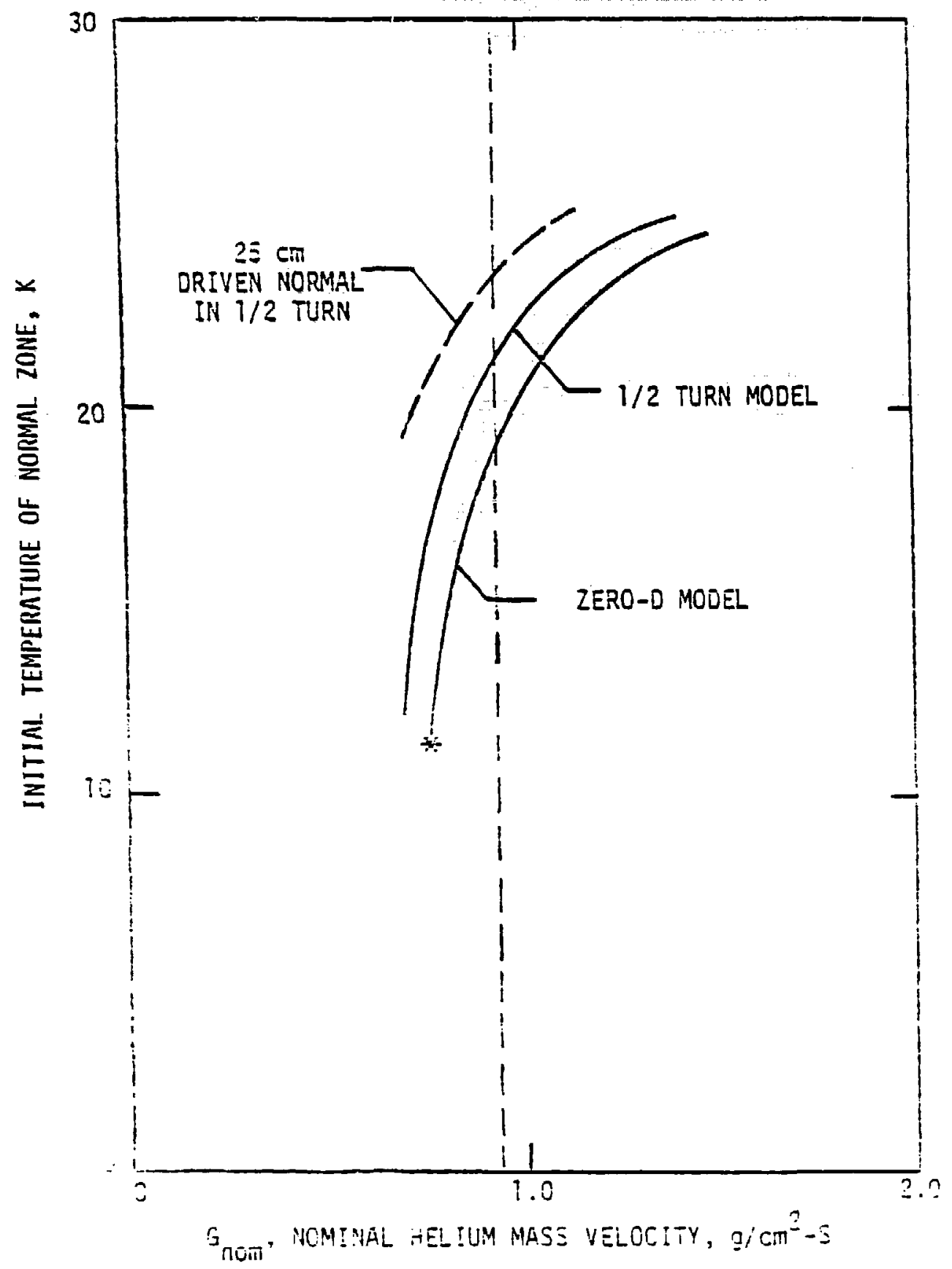

Figure 2. Comparison of the Stability Maps of the Reference Conductor. 


\section{REFERENCES}

1. Chi, J.W. H., J. H. Murphy, and C. K. Jones, "Selection of a Cryostabilized $\mathrm{Nb}_{3}$ Sn Conauctor Cooling System for the Large Coil Porgram, "Proceedings of the Seventh Symposium on Engineering Problems of 'Fusion Research, Volume II, pp. 940-947, October 25, 1977.

2. Heyne, C. J., J. L. Young, and D. T. Hackworth, "Westinghouse Conceptuz 1 Design of a Test Coil for the Large Goil Program," Iden. po 935-939.

3. Sanger, $P$. et al.,. "Design Considerations for the $\mathrm{Nb}_{3} \mathrm{Sn}$ Forced Flow Conductor for LCP," Idem, pp 948-951.

4. Giarratano, 9. J., et al., "Forced Convective Heat Transfer to Supercritical Helium," Cryogenics, Volume 11, October, 1971, p. 385.

5. Hoenic, M. 0, et al., "Supercritical Helium Cooled Cabled Superconducting Hollo\%: Conductors for Large High Field Magnets," Sixth International Crypgen: cs Engineering Conference, Grenobie, France, 1976.

6. Chi, J. W. H., "Efiect of Subchannel flow Velocities on the Stability of Hollow Cak ? 2 Cunductors," PP. of these proceedings. 